Produção Social de Livros Escolares de Química no Brasil, de 1810 a 1941

Lutfi, $M$.

Rev. Virtual Quim., 2012,4 (6), 703-718. Data de publicação na Web: 27 de outubro de 2012

http://www.uff.br/rvq

\title{
Social Production of Chemistry Textbooks in Brazil, 1810-1941
}

Abstract: This is an exhaustive survey of chemistry textbooks written in Brazilian Portuguese, since the deployment of Imprensa Régia in 1810 until 1941. The article put into historical context the books and their authors, by linking them with their publishers, school curriculum and educational legislation through each historical period.

Keywords: Chemistry textbooks; Chemistry Education in Brazil; Authors of Chemistry Textbooks.

\section{Resumo}

Trata-se de um levantamento exaustivo dos livros escolares de química, escritos em português, usados no Brasil desde a implantação da Imprensa Régia em 1810 até 1941. Contextualiza historicamente os autores e os livros produzidos, relacionando-os com as editoras, o currículo escolar e a legislação educacional de cada época.

Palavras-chave: Livros escolares de Química; Educação Química no Brasil; Autores de livros de Química.

\footnotetext{
*Universidade Estadual de Campinas. Campinas, Departamento de Ensino e Práticas Culturais. Faculdade de Educação, Campinas-SP, Brasil.

Mmlutfi@uol.com.br

DOI: 10.5935/1984-6835.20120053
} 
Volume 4, Número 6

\section{Produção Social de Livros Escolares de Química no Brasil, de 1810 a 1941 \\ Mansur Lutfi}

Universidade Estadual de Campinas. Campinas, Departamento de Ensino e Práticas Culturais. Faculdade de Educação, Campinas-SP, Brasil.

* mlutfi@uol.com.br

Recebido em 7 de junho de 2012. Aceito para publicação em 30 de setembro de 2012

\section{Introdução}

2. Metodologia de pesquisa: da coleta de dados à análise

3. Do primeiro ginásio do Império à República

4. Decreto $\mathbf{6 1 3 0}$ de $\mathbf{1}^{\circ}$ de março de $\mathbf{1 8 7 6}$

5. Os Ginásios da República Oligárquica, 1889-1930

6. Reforma do ministro Epitácio Pessoa

7. Reforma de Carlos Maximiliano

8. O Governo Provisório e o Estado Novo de Vargas. Reforma Francisco Campos-, Decreto 19.890, de 18/04/1931

9. Novas editoras em São Paulo

10. Entrevista com Albert Ebert

11. Outras obras publicadas no período de 1930-1941

12. Considerações finais

13. Bibliotecas consultadas

\section{Introdução}

As pesquisas acadêmicas que analisam historicamente 0 conteúdo dos livros escolares de Química no Brasil mostrou que os assuntos entre os capítulos subsequentes são desarticulados, que neles há obstáculos animistas, realistas e verbais ao aprendizado em Química, que as renovações pedagógicas que exijam mudança nas condições materiais de ensino não penetram no ensino de massas, dando margem a que o tecnicismo domine o ensino de Química, e que se baseiam em classificações formais que não acrescentam conhecimento. No entanto, o livro escolar de Química tem uma história de permanência de ao menos 200 anos no Brasil. Quem foram os autores desses manuais? Em quais instituições se formaram 
e atuaram? Quais as motivações para os escreverem? Quem os editou? A que consumidores se destinavam?

\section{Metodologia de pesquisa: da coleta de dados à análise}

Para tentar elucidar essas questões, buscamos os livros escolares de Química tombados na Biblioteca Nacional e no Colégio Pedro II, no Rio de Janeiro; na Biblioteca da Faculdade de Educação da USP; na Biblioteca do Conjunto de Química da USP; na Biblioteca Joel Martins da FE-Unicamp; na Biblioteca da UNESP-Marília; na Biblioteca do Acervo da Editora IBEP- Nacional; na BnF, Bibliothèque Nationale de France, Paris e na Biblioteca Pública de Pernambuco, Recife.

Utilizando-se da ficha de pesquisa do LIVRES, foram anotados os nomes dos livros, os autores, o número de páginas, o número da edição, a editora e o ano de publicação dos exemplares por nós encontrados.

Procurou-se relacionar cada obra com a vida profissional do autor, com o momento histórico, com os interesses conflitantes desse momento, com a legislação, a grade curricular e o currículo em cada período da história do Brasil: Império, ạ República, Governo Provisório e Estado Novo, Ditadura Militar, Redemocratização.

\section{Do primeiro ginásio do Império à República}

Em 1837 ocorreu a fundação do Imperial Collegio de Pedro II, no Rio de Janeiro, no prédio do então Colégio de São Joaquim. Deveria servir de modelo para os outros que se abrissem nas províncias. Em São Paulo, só sessenta anos depois se abriram os três primeiros ginásios estaduais.

O Ginásio era composto de oito séries e havia aulas de Sciencias Physicas nas três últimas. As noções de Química estavam incluídas nessa disciplina. Os livros utilizados durante o século XIX para o ensino de Física e Química foram elaborados por professores do Colégio de Pedro II ou da Faculdade de Medicina, onde havia cátedras de Química. Em alguns casos, como se pode ver a seguir, houve professores que atuavam nos dois estabelecimentos simultaneamente e usavam o mesmo livro. Houve também importação de livros de autores portugueses.

Os primeiros textos por nós encontrados são de professores da Escola Militar no Rio de Janeiro. Daniel GARDNER (1785-1831) já lecionava Química no Colégio de São Joaquim desde 1809 e faleceu antes de esse se transformar no Colégio Pedro II. Gardner foi também grande propagador da Química, através de palestras anunciadas na Gazeta do Rio de Janeiro em 1810. As experiências químicas realizadas durante as palestras garantiam o sucesso desses eventos, pois preenchiam a expectativa de uma plateia ávida por curiosidades científicas. 0 médico escocês Daniel Gardner era membro da Sociedade Filosófica e Matemática de Londres, cidade onde se faziam essas palestras públicas. Foi professor de Química, tendo escrito o primeiro livro, segundo Nadja Paraense Santos e Carlos A. L. Filgueiras, produzido no país para o ensino na Academia Real Militar, denominado Syllabus ou Compendio das Lições de Chymica, publicado pela Impressão Régia, em 1810.

No período de 1833 a 1846 sucederam a Gardner na cadeira de Química da Academia Militar, João da Silveira Caldeira (1800-1859) e frei Custódio Alves Serrão, que acumularam esta função com a de diretor do Museu Imperial.

Outro livro foi o do frei carmelita Custódio Alves SERRÃO (Alcântara- MA, 1799 a Rio de Janeiro, 1873), Lições de Chimica e Mineralogia, publicado no Rio de Janeiro, em 1833 pela Typographia Imperial e Nacional.

Qual era a formação de Serrão? Em 1814, aos 15 anos, ele foi a Coimbra sob expensas da Ordem Carmelita para ter aulas de Cursos Superiores, mas rebelou-se contra os frades de Coimbra porque queria cursar Ciências 
Naturais. Já com o diploma veio para o Rio de Janeiro, sendo nomeado lente de Botânica e Zoologia da Academia Imperial Militar, e posteriormente lente de Química e Mineralogia. Em 1828 foi nomeado o terceiro diretor do Museu Imperial e Nacional (18281847) e integrou, em 1834, a comissão responsável por melhorar o funcionamento da Casa da Moeda, instituindo uma reforma nos processos de análise e refinamento de metais, considerada inédita. ${ }^{1}$

Outro autor foi Pedro de Alcântara BELLEGARDE (1807-1864) que escreveu Noções de Chimica, de 25p, no Rio de Janeiro, pela Typographia J. E. S. Cabral, em 1839. Bellegarde foi sócio fundador do Instituto Histórico e Geográfico do Brasil, autor de Compendio de architectura civil e hydraulica, no Rio de Janeiro, pela Typ. M. A. da Silva Lima, em 1848 e da Carta corographica da província do Rio de Janeiro em 1863.

Entre 1850 e 1852 realizam-se Conferências públicas sobre Química no Museu Imperial e Nacional, por Francisco Ferreira de Abreu, introduzindo o uso de fórmulas e equações químicas no Brasil, seguindo a concepção de Berzelius.

Em 1841 ocorreu a primeira modificação dos estatutos do Colégio de Pedro II, alterando seu plano de estudos e fixando em sete anos o curso completo, com latim nos sete e grego nos quatro últimos. Esse currículo tem a marca do Humanismo, no caso, a concepção de que são o Latim e o Grego que promovem o desenvolvimento intelectual, e não se aprendia Língua Portuguesa. A disciplina Sciencias Physicas passa a ter, até 1876 , três aulas semanais de 60 min e apenas no 60 ano, a disciplina muda de nome de Sciencias Physicas para Physica e Chimica. Os livros para essa disciplina são em um volume único até 1898, quando a disciplina passa a aparecer em três séries.

Entre os livros de Química desse período, 1841-1882, estão o de Martim Affonso Barbosa da SYLVA, Chave da Chimica: ou novo methodo para estudar esta sciencia. Foi publicado no Rio de Janeiro pela editora de Eduardo e Henrique Laemmert, em 1861. João Martins TEIXEIRA (1848-?), que era professor de Física Médica da Faculdade de Medicina do RJ, publicou Noções de Chimica Geral, Baseadas nas douctrinas modernas, de 378p, em 1875 e Noções de Chimica Inorgânica, de 707 p., em 1878, ambos com 1á ed. no Rio de Janeiro, pela editora de Serafim José Alves, em 1875. Os livros de Teixeira serão os livros escolares mais utilizados até o começo do século $X X$, com publicação até a 4a ed., pela Francisco Alves, em 1898.

Ayres de Albuquerque GAMA (1833-1889) escreveu Noções de Physica e Chimica, de 155p, no Rio de Janeiro, pela Ed. Eduardo \& Henrique Laemmert, s/d. Esse livro tem uma segunda edição em 1876, "inteiramente refundida e augmentada". Nesse livro consta que ele foi "aprovado para a Escola Normal de Pernambuco". Ayres Gama era professor de Aritmética da Escola Anexa da Faculdade de Direito de Pernambuco e filho do 1으 Visconde de Goiana.

\section{Decreto 6.130 de $1^{\circ}$ de março de 1876}

As aulas da disciplina Physica e Chimica voltam ao 60 ano, com seis aulas por semana, de segunda-feira a sábado. Em 1882 há uma mudança e as seis aulas de Physica e Chimica passam todas da 6a para a 5a série, de uma hora de duração, de segunda-feira a sábado.

Nesse período temos a publicação, em Lisboa, Portugal, da Bibliotheca do Povo e das Escolas, sob a direção de Xavier da Cunha, sem nome dos autores, pela Ed. David Corrazzi. Todos os exemplares têm $64 p$, são eles, Principios Geraes de Chimica, em 1881(BPE 17); Chimica Inorganica, em 1882 (BPE 27) e Chimica Organica, em 1882. José Júlio Rodrigues aparece como participante na elaboração desses livros.

Sir Henry Enfield ROSCOE (1833-1915) 
escreveu o livro Chimica, de 119p, que foi adaptado ao português por Carlos Jansen, e publicado no Rio de Janeiro, pela Laemmert, em 1882, fazendo parte da Biblioteca do Ensino Intuitivo, Série Sciencias Naturaes, em quatro volumes. Carlos Jansen era professor do Colégio de Pedro II e fez também adaptações de histórias infantis para Ed. Laemmert.

\section{Os Ginásios da República Oligárquica, 1889-1930}

Após a Proclamação da República, novo Regulamento da Instrução Primária e Secundária do Distrito Federal foi conferido por meio do decreto 891 de 08/11/1890, aprovado pelo Governo Provisório do Marechal Deodoro da Fonseca e referendado pelo Ministro da Instrução Pública, Correios e Telégrafos, Benjamin Constant Botelho de Magalhães.

A Instrução Secundária continuou com a mesma estrutura de sete anos e as aulas da disciplina Physica e Chimica continuaram na 5a série, de segunda a sábado.Pelo Plano de Reforma de 28/12/1892 continua igual. Pelo Regulamento para o Ginásio Nacional (nome republicano do Colégio de Pedro II) e Ensino Secundário nos estados, aprovado pelo Decreto 2.857 de 30/03/1898, para a disciplina Physica e Chimica, passam a serem três aulas na quinta série, duas na sexta série e uma na sétima série, mantendo-se o total de seis horas-aula semanais.

Pelo Regulamento do Ginásio Nacional aprovado pelo decreto 3.251 de 08/04/1899, o Ensino Secundário passa de sete para seis anos. A carga horária de Physica e Chimica passa a ser de cinco aulas na quinta série e uma na sexta série.

Os livros editados no Rio de Janeiro no período são os de Álvaro Joaquim de OLIVEIRA, Elementos de Chimica Geral, de 851 p, com 1a ed. pela H. Garnier, em 1889; e 2a ed. em 1898. Bem como os Apontamentos de Chimica, pela Lombaerts, em 1883.
Álvaro Joaquim de Oliveira foi engenheiro militar e autor de Apontamentos de Chimica, livro que o implantador do curso de Química da USP, Heinrich Rheinboldt, em 1955, considerava a melhor e mais original obra brasileira nesse campo. Rheinboldt observa que Álvaro de Oliveira foi, com Benjamin Constant Botelho de Magalhães, um dos fundadores da Sociedade Positivista, e talvez por essa razão fosse levado a defender a teoria da constância da valência de modo tão unilateral que isso deu ao seu livro um traço peculiar. A posição de Rheinboldt com respeito ao positivismo brasileiro era marcada por uma perplexidade cautelosa: É muito peculiar que essa doutrina, que indica claramente os caminhos que devem ser seguidos na futura pesquisa química, o que levou J. H. van't Hoff, por exemplo, a fazer descobertas maravilhosas, não detonou 0 que era tão necessário no Brasil: a abolição do velho sistema de ensino decorado, e o nascimento da pesquisa pura. Nem o próprio Álvaro de Oliveira fez uma única experiência original. $^{2}$

O mesmo João Martins TEIXEIRA, citado anteriormente, publicou Noções de Chimica Geral, de $384 p$, do qual localizamos um exemplar da 3 a ed, de 1893, pela Francisco Alves, do Rio de Janeiro; e localizamos exemplares da 4ed, em 1898; 9ạ ed, em 1913; 14a ed. em 1926; até 16a ed. em 1931.

É de Teixeira também, Noções de Chimica Inorgânica, com 707p, com 2a ed. no Rio de Janeiro pela Serafim José Alves, em 1894, até a 5a ed. em 1906. As edições posteriores saíram pela Francisco Alves, como a 7a ed. em 1913 até a 14a ed. em 1930.

O professor da École Normale Sorbonne e da Faculté des Sciences de Paris, Louis-Joseph TROOST (Paris, 1825-1911) escreveu, e foi traduzido para o português, o Compendio de Chimica, de $428 p$, publicado no Rio de Janeiro pela Garnier e impresso em Paris pela Typ. Garnier, em 1900. Escreveu também o Traité Elementaire de Chimie e o Precis de Chimie. 


\section{Reforma do ministro Epitácio} Pessoa

Pelo Decreto 3 914, de 26/01/1901 temos quatro aulas na 5 a série e três na $6 \underline{a}$ série.

O português Rui Teles PALHINHA (18711957) publicou em 1901 os Elementos de Chimica. Seguidos d'umas breves noções de mineralogia, 10 ano, com 190p, e $1 \underline{a}$ ed. em Paris e Lisboa, pela Aillaud.

Rui Teles Palhinha, com o nome por vezes grafado Ruy Telles Palhinha (Angra do Heroísmo, Açores, 1871 - Lisboa, 1957) foi botânico e professor universitário a quem se deve a exploração sistemática da flora açoriana. Foi diretor do Jardim Botânico de Lisboa, foi também formado em Filosofia pela Universidade de Coimbra em 1893.

O decreto 8660 de 05/04/1911 é aprovado pelo Presidente Mal. Hermes da Fonseca e referendado pelo Ministro do Estado da Justiça e Negócios Interiores, Rivadávia da Cunha Corrêa. Pelo Regulamento do Colégio Pedro II passa a haver três aulas na 5 a e três na $6^{a}$ série.

Uma prática desse período é a impressão de livros das várias disciplinas na França, como o de José Júlio RODRIGUES (18451923), Curso Elementar de Chimica Geral. Introdução Theorica ao Estudo de Chimica sob um ponto de vista elementar, de $217 \mathrm{p}$, impresso em Paris pela Ed. Aillaud e Bertrand, em 1912.

Maximino MACIEL (Rosário-SE, 1866 a RJ, 1923), formado em Direito e em Medicina, e professor catedrático de Português no Colégio Militar, publicou no Rio de Janeiro os Elementos de Chimica Geral, de 328p, pela Francisco Alves, com 2a ed. em 1912 e 3 a ed., em 1932.

Sempre no Rio de Janeiro, Pedro Augusto PINTO (1882-1971) publicou em 1908 as Noções de Chimica Geral, de 385p, pela J. Ribeiro dos Santos; com 2a ed. de 328p pela Francisco Alves \& Cia, em 1913. Pela Francisco Alves, em 1909, publicou
Metaloides e seus compostos, com 436p, e Metais e seus compostos, com 436p. A Química na Vida Cotidiana, com 221p, saiu em 1934.

As Noções rudimentares de Chimica descritiva, com 180p, foram impressas pela Typ. Revista dos Tribunais, em 1922 e os Rudimentos de Química, em 6a ed., pela Tip. Misericórdia, 1936; com 7ạ ed. em 1940. Em colaboração com Francisco VENANCIO Fo escreveu Elementos de Química, mas não localizei nenhum exemplar deste livro.

Pedro Augusto Pinto foi professor de Farmacologia e Arte de formular da Fac. de Medicina do Rio de Janeiro entre 1904 e 1950 e também professor na Escola Paulo de Frontin. Vamos nos deter em Pedro Augusto Pinto e ver qual era o perfil de um autor de livro para o ensino de Química no começo do séc. XX. Vamos ler um relato de A. L. Oliveira que traça um pouco do que ele fazia.

"Nas conversas com a noiva o Lourenço se referiu com respeito e admiração ao filólogo Pedro Augusto Pinto, de quem adquirira todos os livros. Desta vez, ambos se surpreenderam. Ela conhecia pessoalmente o doutor Pedro, também médico, catedrático de Farmacologia da Faculdade de Medicina do Rio de Janeiro, que dividia os interesses do campo médico com os dos estudos da língua. Essa função se verifica bem no seu Dicionário de termos médicos. Ao lado de livros com lições de Farmacologia Clínica e Bio-Experimental, de noções de Farmácia Galênica, de propriedade dos corpos, e tantos outros no gênero, Pedro Pinto publicara: Dicionários de Sinônimos, Locuções e Expressões na Réplica de Rui Barbosa, Fatos da Língua; Brasileirismos e Supostos Brasileirismos em Os Sertões de Euclides da Cunha; Estudos de Etimologias, Nugas $e$ rusgas na linguagem; A língua materna. Em edições sucessivas.

Lourenço estava bem familiarizado com os livros de Pedro Pinto no setor de língua. Hoje, na sua biblioteca, localizo a Revista Filológica, de abril-maio de 1955, cujo redator chefe era Serafim da Silva Neto, que traz um artigo de 
Pedro Pinto com o título "Linguagem Científica". Está claro que o interesse de Lourenço era toda a revista, mas o artigo tinha um significado todo especial.

O jovem Pedro trabalhara algum tempo na farmácia do pai da esposa do Lourenço. $\mathrm{E}$ se revelara muito inteligente e interessado na leitura em geral e na análise das receitas médicas que iam sendo aviadas na farmácia. Um dia, o jovem Pedro Pinto, que era muito querido de toda a família Lisboa, disse que iria para o Rio estudar. E foi, fez seus vestibulares, estudou Medicina, formou-se, fez concursos de cátedra com defesa de tese e se projetou na Capital.

Para o Lourenço o que interessava mais era o filólogo, mas sentia curiosidade, interesse pela pessoa do Mestre. E assim quando se casou, e foi passar a lua-de-mel no Rio, quis conhecer pessoalmente o seu colega mais velho e de nomeada. É bom lembrar, aqui, o encontro de dois filólogos ou dois linguistas. Com que interesse mantiveram altas cogitações filológicas ou linguísticas. As esposas, a de Pedro Pinto e a de Lourenço, ouviam encantadas aquela conversa de alto nível e pressentiam nos dois o amor pela nossa língua.

Às despedidas, o Pedro Pinto, como numa auto-análise, advertiu a recém-casada: "Não estranhe se seu marido vier a ter algumas exigências em casa, vier a preocupar-se com especificações, a ter mesmo alguma impertinência em minúcias, coisa própria de filólogos. Compreenda isso sempre."

Era então o ano de 1936. Hoje, percorrendo as estantes de Lourenço, encontro a sétima edição do Dicionário de termos médicos, 1958, com esta dedicatória: "Ao muito estimado casal Alaíde Lisboa de Oliveira e José Lourenço de Oliveira, lembrança carinhosa de Pedro A. Pinto". ${ }^{3}$

\section{Reforma de Carlos Maximiliano}

Pelo decreto 11.530, de 18/03/1915, aprovado pelo Presidente da República,
Wenceslau Braz e referendado pelo Ministro da Justiça e Negócios Interiores, Carlos Maximiliano Pereira dos Santos, a Escola Secundária passa de seis para cinco anos de duração. A disciplina Physica e Chimica passa a ter três aulas na 4a a série e três na 5a série. Nas reformas de 1916 e 1919 continuou igual.

Augusto Xavier Oliveira de MENEZES, médico pela Fac. de Medicina do Rio de Janeiro e professor catedrático do Collegio Pedro II publica Noções succintas de Chimica Philosophica, com 131p, com 2a ed., no Rio de Janeiro pela Jacintho Ribeiro dos Santos, em 1917 e 4a ed. com 320p "Correcta e consideravelmente augmentada com $\mathrm{O}$ ultimo programa do Collegio Pedro II", em 1929.

Em 1920 era publicada uma nova edição de um livro para o Curso Médio da disciplina PHYSICA E CHIMICA, por uma reunião de professores. Era o "Programa de Admissão a várias Escolas Superiores", "com 286 Figuras Intercaladas no Texto". Outro semelhante foi o F. T. D. Noções de sciencias physicas e naturaes, Chimica com 68 figuras intercaladas no texto. Curso Médio. Programa de admissão a várias Escolas Superiores por uma reunião de professores. Nova edição, com 203p, publicado no RJ pela Livr. Paulo Azevedo, em 1921.

Era da editora F.T.D.(Frère Theophane Durand) que tinha o hábito de não colocar o nome dos frères autores e tradutores. A venda no Brasil estava a cargo da Livraria Francisco Alves \& Cia. Foi impresso em Lyon, por Emmanuel Vitte, 1920. O conteúdo de Química, que vai da p. 257 até p. 458, é basicamente de Química Inorgânica, descritiva. Uma espécie de Dicionário Enciclopédico que vai definindo termos. Cada noção tem um número, um ponto. Por exemplo:

145. Louças. -Sob o nome de louças designam-se todos os objectos fabricados com argila e endurecidos em seguida pela acção do calor. Há quatro especies principaes de louças: a porcelana, a faiança, as louças communs e os barros cozidos. 
146. Porcelanas. - A porcelana se faz com o kaolim, que é argila muito dura. O kaolim é uma substância branca compacta, macia ao tacto e difficilmente fusivel; encontra-se em abundancia em Saint-Yrieix, perto de Limoges, e na Saxonia. Ao kaolim, accrescenta-se um fundente que tem por objecto diminuir-lhe a contracção durante o cozimento e fazer-lhe experimentar um começo de fusão, o que o torna vitreo e translucido. O fundente empregado é o feldspatho, silicato duplo de aluminio e potassio.

147. Faiança. Fabrica-se a faiança com argila plastica á qual se ajunta quartzo reduzido a pó impalpavel. Os objectos, depois de sua fabricação, são primeiro submettidos a uma primeira cozedura, em seguida recobertos de um verniz fusivel, composto de quartzo, de carbonato de potassio, de minio e de oxydo de estanho. Uma segunda cozedura derrete o verniz, que forma na superficie dos objetos uma camada de esmalte muito branco.

Essa Química Inorgânica não tem um caráter tecnológico, pois não se abordam os conceitos químicos envolvidos que levam a uma transformação. Não se pensa a matéria em termos de relação estrutura-função, sua estrutura atômico-molecular, embora já conhecida em 1920, não é evocada para explicar suas propriedades.

Em 1907, Tibúrcio Valeriano Pecegueiro do AMARAL, formado pela Escola de Medicina do Rio de Janeiro e nela catedrático de Química Médica, professor de Física e Química em institutos de instrução secundária como a Escola Normal, escreveu Elementos de Chimica inorganica, com 518p, com 1a ed. pelo Inst. de Artes Gráficas e 4a ed. em 1921. Concomitantemente publicou Noções Elementares de Chimica Organica. Para uso dos alumnos d'esta disciplina nos Gymnasios e Escolas Superiores da Republica, com $373 p$, 1a ed. pela Imprensa Nacional, em 1907 ( 2 a ed., 1908/ 3a ed., 1913/ 4a ed., 1919/ 5a ed., 1921/ 6a ed., 1924/ 7a ed., 1927/ 8a ed., 1932).
Ernesto SILVA, em Recife, 1922 publicou Elementos de Chimica Geral, com 90p, pela Imprensa Industrial.

O padre Leonel Edgard da Silveira FRANCA (1893-1948), em sua vasta obra, escreveu em 1919, no RJ, também os Apontamentos de Chimica Geral. Organizado de accordo com o programa official para uso dos preparatorianos e candidatos às Escolas Superiores; com 140p, publicado por Pimenta de Melo, com 6a ed., em 1933; e 9a ed., s.d.

Leonel E. S. Franca (São Gabriel-RS, 06/01/1893 a 03/09/1948), de família baiana, homem de profunda influência cultural e religiosa no Brasil, dedicou seus últimos dez anos à fundação e consolidação da primeira universidade particular do país. Ingressou na Companhia de Jesus em 1908, depois de completados os estudos no Colégio Anchieta em Nova Friburgo, RJ. Completou estudos em Roma. De volta ao Brasil, Leonel Franca ensinou aos estudantes jesuítas no Colégio Anchieta, em Nova Friburgo. Voltou ao Rio em 1915 e iniciou o magistério no Colégio Santo Inácio, chegando a reitor. Leonel Franca escreveu o Ratio Studiorum, em que relata qual era o método de ensino dos jesuítas.

Foi nomeado para o Conselho Nacional de Educação, do qual tinha sido um dos fundadores em 1931. Em 1939, o Concílio Plenário dos Bispos do Brasil decidiu criar a Universidade Católica do Brasil, no Rio de Janeiro. Dom Sebastião Leme, Cardeal Arcebispo do Rio encarregou seu conselheiro, Franca, de incumbir-se desta missão. Em outubro de 1940, decreto Presidencial criava as "Faculdades Católicas", que começaram a funcionar no ano seguinte, tendo como seu Reitor o próprio Franca. Em 1945 as "Faculdades Católicas" passariam a ser Universidade e dois anos depois, Pontifícia Universidade Católica do Rio de Janeiro, PUCRJ.

\section{Reforma Rocha Vaz}

A reforma de 1925 foi proposta pelo decreto $16.782-A$ de 13/01/1925, assinado pelo Presidente da República Arthur 
Bernardes e o Ministro da Justiça e Negócios Interiores João Luiz Alves. O nome Rocha Vaz deveu-se à participação do diretor da Faculdade de Medicina do Rio de Janeiro, Juvenil da Rocha Vaz, na elaboração da reforma. Objetivando uma reorganização do ensino secundário e superior, propunha que o ensino superior deveria abranger os cursos de Direito, Medicina, Engenharia, Farmácia e Odontologia (art.33).

Pela Reforma Rocha Vaz, a Escola Secundária volta a ter seis anos. As disciplinas Physica e Chimica passam a ser separadas, com três aulas semanais cada uma, na 4ạ e na 5a séries.

É notável a presença de professores da Faculdade de Medicina do Rio de Janeiro entre os autores de livros didáticos de Química. Mas se víssemos qual era o currículo de um curso de Medicina logo após a proclamação da República, tão diferente do atual, perceberíamos a forte presença do grupo das Ciências Físicas e Naturais no currículo: Física médica, Química Inorgânica Médica, Química Orgânica e Biológica, Química Analítica e Toxicológica, Botânica e Zoologia Médicas, Farmacologia e Arte de formular. As disciplinas de química foram posteriormente agrupadas na Química Médica.

\section{O Governo Provisório e o Estado Novo de Vargas. Reforma Francisco Campos', Decreto 19.890 , de $18 / 04 / 1931$}

A nova reforma foi determinada pelo decreto 19.851, de 11/04/1931, assinado pelo Chefe do Governo Provisório, Getúlio Vargas, e pelo Ministro da Educação e Saúde Pública, Francisco Campos, e definia que o ensino superior no país deveria seguir o sistema universitário, segundo os dispositivos dos Estatutos das Universidades Brasileiras, incluso no referido decreto.

A Reforma Francisco Campos, Decreto 19.890 de 18/04/1931 divide o Curso
Secundário em duas partes, o Curso Secundário Fundamental, com cinco anos, tendo duas aulas semanais de Química e duas de Física nas 3a a 4a e 5a séries. A segunda parte é o Curso Secundário Complementar, em dois anos, preparatório às Escolas Superiores.

Vamos intercalar a esse texto, trechos da entrevista concedida ao autor, no Rio de Janeiro, em julho de 2005 pelo professor de Química, Albert Ebert.

Em que livro de química o senhor estudou no Secundário Complementar?

Dirige-se para uma estante na sala.

Eu queria te mostrar o "Barros Terra", mas não estou encontrando. Aqui tem o Geraldo Camargo e Saffioti; Lições de Química, de Prudente e Sena, (da Livraria Simões Lopes, Rua do Almada, 123, Porto. 1943).

Encontra na estante o livro que estava procurando: Esse era o melhor livro de Química Orgânica da época, Chimica Organica Teorica, do Dr. Barros Terra. (continuando na estante) Esse é o de Química Analítica, do Otto Alcides, do RS; esse é de Biologia Educacional, do Almeida Júnior. Esse é o livro do Gildásio Amado (catedrático do Colégio Pedro II, livro da Cia. Editora Nacional, de 1961, para o 10 colegial).

Resumos de Química, para os Cursos Ginasial e Complementar, Livraria Lusitana, Rua Riachuelo, 906, Rio de Janeiro, 1941. Esse é do tempo em que se falava em Curso Complementar, que seria um curso que se fazia após o Ginásio e antes da Faculdade.

Vamos interromper a entrevista e continuar com o texto. O Curso Secundário Complementar vai ser mais conhecido como Preparatório às Escolas Superiores ou Classes Preparatórias, ou Curso Médio. Com a autonomia da disciplina Química no Curso Secundário Fundamental e no Secundário Complementar, aparecem novos livros específicos para seus ramos. Seus autores são Francisco VENANCIO Fo; Antonio Valente do COUTO; João Batista Pecegueiro do AMARAL; Miguel Tenório d' ALBUQUERQUE. Seus livros 
serão abordados em um tópico abaixo. Vamos comentar aqui o de J. BASIN.

O livro do francês J. BASIN, professor agrégé do Lycée de Lille, foi traduzido para Lições de Chimica, com três volumes e publicado no Rio de Janeiro pela Francisco Alves, em 1915. Consta do Tomo I: Química geral e Metalóides. II: Metais. III: Química orgânica e análise. O livro de Basin foi reimpresso na França, em Lyon; 18 , rue de la Quarantaine e distribuído pela Livraria Paulo de Azevedo, sucessora da Francisco Alves.

Vamos transcrever um trecho do livro de J. Basin para se ter uma idéia de como era o texto desses livros escolares do período.

121. Leis da solubilidade dos sólidos nos líquidos.

10 Nas mesmas condições de temperatura e de pressão, o coeficiente de solubilidade é fixo para um mesmo soluto no mesmo solvente. Assim, a 150 centígrados, 100 grs de água dissolvem 5,2 grs de azotato de bário; esta concentração não póde exceder este limite; uma nova quantidade de sal, posta em contato com o líquido, não se dissolve mais. A dissolução e o excesso de sal sólido, que não se dissolve, formam um equilíbrio independente de suas massas respectivas.

Mas um solvente saturado por um sal não se acha impossibilitado de dissolver outros corpos. A água, saturada de azotato de bário, póde dissolver ainda sal marinho. E o mais notável é que, depois de ter dissolvido este último sal, torna-se capaz de dissolver novas quantidades de azotato de bário... A razão disso é que os dois sais, diferindo entre si pelo ácido e pela base, dá-se entre eles uma dupla troca, de modo que, em realidade, há quatro sais na mistura: $\left(\mathrm{AzO}^{3}\right)^{2} \mathrm{Ba}, \mathrm{ClNa}$, $A z O^{3} \mathrm{Na}$, e $\mathrm{Cl}^{2} \mathrm{Ba}$, o que tem por efeito diminuir a concentração de cada um.

Em geral, se o novo sal introduzido não difere do da solução senão pelo ácido, será nela menos solúvel do que no solvente puro: assim, a água saturada de CIK dissolve menos $\mathrm{AzO}^{3} \mathrm{~K}$ do que a água pura.

2- Em geral, o coeficiente de solubilidade cresce com a temperatura do solvente. Assim, o coeficiente do azotato de bário, que é de 5,2 a 15 으, é de 32 a 100 .

O livro é reimpresso em 1932 em Lyon, na França, e vendido no Brasil pela Livraria Paulo de Azevedo (relacionada com a Livraria Francisco Alves). A Editora é a FTD, uma editora religiosa, dos Irmãos Maristas.

O exemplo escolhido é completamente fora do senso comum. Mas no Brasil o ponto é para ser decorado, não para ser aprendido.

Não é só a impressão que é francesa. Em toda a estrutura e conteúdo do livro se percebe a influência. A divisão do texto do livro em pontos numerados (este é o 121.) que contém uma informação fechada, sem se relacionar com outros itens. Dentro do texto, um trecho com a informação principal é apresentado em caracteres maiores, seguido de outro, com informações suplementares é apresentado em letras menores, indicando que o aluno deve se preocupar mais com a primeira parte.

Também a nomenclatura segue o padrão francês, chamando, por exemplo, o nitrogênio de azoto. E também, nas fórmulas, o uso dos números como expoente.

As ênfases são no ensino da nomenclatura e no das propriedades das substâncias químicas e para esse último se faz referência constante ao uso consuetudinário e industrial das substâncias. Por isso é bastante descritivo, como se pode ver aqui em outro trecho:

500. Aplicações do fósforo vermelho. Nos laboratórios, serve para realizar certas reações perigosas com o fósforo branco. $\mathrm{Na}$ indústria, serve para fabricar os chamados fósforos de segurança.

No Brasil, todos os fósforos são de segurança e fabricados pelo método sueco. A massa inflamável é composta de clorato de potássio (100grs), sulfureto de antimônio (40grs), e cola forte (20grs). As caixinhas têm um lado pintado com uma massa de fósforo vermelho (100grs), sulfureto de antimônio (80grs), e cola forte (50grs); esfregados em 
qualquer outro lugar que não nessa massa, os fósforos de segurança não se acendem.

Atualmente, fabricam-se mesmo palitos de fósforos sem fósforo; de sorte que já não há mais pretexto para se deixar nas mãos de todos, uma substância tão inflamável e tão tóxica como o fósforo.

Ou neste: 318. Cloretos descorantes. - Os cloretos descorantes são compostos cuja base é o cloro, utilizados para alvejar os tecidos e desinfetar as salas; são muito instáveis e desprendem o seu clóro sob a influência dos ácidos, ainda os mais fracos, como o ácido carbónico. Empregam-se tres cloretos descorantes: a água de Javel, o licor de Labarraque e o cloreto de cal.

\section{Novas editoras em São Paulo}

A década de 30 é aquela em que há uma transição. Os autores e as editoras mais importantes começam a aparecer em São Paulo e Porto Alegre e o Rio de Janeiro começa a perder importância. Em São Paulo inauguram-se a Nacional, a Melhoramentos e a do Brasil. Entre os autores do período estão Miguel MILANO, Victor GODINHO, Sebastião LOBO.

Com a nova grade curricular que propõem duas aulas semanais de Química na 3ạa 4a e 5a séries, Gildásio AMADO (1906-1976), professor do Colégio Pedro II publica em São Paulo, pela Cia. Ed. Nacional e pela Ed. Globo de Porto Alegre os livros de título: QUÍMICA, para o Curso Secundário.

No Rio Grande do Sul, de Ignacio PUIG, S. J. (Manresa, 1887- Barcelona, 1961) foram traduzidos para o português e publicados pela Ed. Globo. O sacerdote jesuíta catalão Puig foi professor do Instituto de Química de Sarriá, Barcelona; subdiretor do Observatório do rio Ebro, em Tortosa.

José Coelho de Almeida COUSIN (18971991) escreveu Pontos de Química. Rigorosamente de acordo com o programa da 3a série do Curso Fundamental, de 261p, publicado em 1937 pela Francisco Alves.
Segundo Afrânio Coutinho, Cousin era poeta, cronista, ensaísta, crítico, jornalista, farmacêutico, advogado. Tinha registro de professor de Português, Química, História Geral e do Brasil. Nasceu em SacramentoMG, a 15/12/1897. Faleceu no Rio de Janeiro a 13/03/1991. Aprendeu as primeiras letras com a avó francesa, Victorine Cousin. Cursou o Ginásio Mineiro, em Belo Horizonte e o Colégio Pedro II. Formou-se em Farmácia, pela Universidade de Ouro Preto (1920) e em Ciências Jurídicas e Sociais, em Vitória (ES) em 1936. Foi empregado de fazenda, balconista, escriturário, farmacêutico. $\mathrm{Na}$ década de 30, foi redator da revista "Vida Capixaba" e colaborou em vários órgãos da imprensa do Espírito Santo.

Mudou-se para o RJ, onde militou nos meios jornalísticos e como professor de História do Colégio Pedro II. Foi catedrático de Química Analítica da Faculdade de Farmácia e Odontologia de Vitória, no Ginásio do Espírito Santo, onde lecionou História; no Liceu "Nilo Peçanha" em Niterói (História) e do curso complementar Préjurídico, como professor de Literatura. (...).

Outros autores foram desse período Mário MARCIANO, Tristão Feijó FERREIRA, J. B. P. AMARAL, Álvaro Soares BRANDÃO, Fernando Nogueira PINTO e José de Bittencourt RODRIGUES, Mário FACCINI, médico no Rio de Janeiro, professor de Física, Química e História Natural; George SUMNER, professor catedrático de Matemática do Colégio Pedro II; Arlindo Michalscki FRÓES, C. H. LIBERALLI e Djalma HESSELMANN. São autores com uma divulgação restrita de suas obras e cujos livros estão detalhados em tópico abaixo.

Fernando de Azevedo organizou na Editora Nacional a coleção Biblioteca Pedagógica Brasileira da qual constava a Série II, Livros Didáticos. Fazem parte dessa série os livros de Coriolano M. MARTINS (? 1935). Chimica didactica para os cursos das 3a , 4a e 5a série gymnasiaes, commerciaes e pre-superiores; Innumeros problemas resolvidos de $444 p$, com 2ed pela Nacional, em 1936. É um volume único para as três séries. (BEB). Coriolano Martins foi secretário 
da Academia Brasileira de Ciências. Foi lente da Escola de Engenharia Mackenzie e do Colégio Ypiranga. Escreveu o correspondente de Física.

Arnaldo Carneiro LEÃO (Recife 1887 a RJ 1966) era médico, professor da Escola de Aperfeiçoamento, Assistente Técnico de Ciências Físicas e Naturais da Escola Normal Oficial no Recife. Assistente Extraordinário da Cadeira de Física e Biologia da Faculdade de Medicina. Professor de Física, Química e História Natural do Instituto Carneiro Leão, de Recife. Os seus livros têm muitas atividades práticas, bem ao estilo da Escola Nova. Leão escreveu em Recife: Escola Nova (Metodologia das Ciências Físicas e Naturais). Escreveu também livros de Física e de Ciências Naturais. Publicou em 1936, pela Ed. Nacional o livro, Química. Iniciação aos estudos dos fenômenos químicos. 3a série ginasial, $1 \stackrel{\circ}{\circ}$ vol., com 302p. Esse livro teve uma tiragem de quatro mil na 1 a ed., cinco mil na 2 a ed., em 37 e 4,5 mil na 3 ạ ed., em 1940, números grandiosos para a época. A 5ed, em 1942 saiu pela Ed. São Paulo. Publicou também Química para a 4a série, $1^{\underline{a}}$ ed. em 1939 e 2a ed. em 1942.

E Oscar Bergström LOURENÇO escreve para a Nacional, Chimica para a 3 a série e Química, Iniciação no estudo da Química Experimental para a 3 a série ginasial, em 1936. (BPB, s. II. v. 52). Lourenço era engenheiro químico, professor no Liceu Nacional Rio Branco e químico do IPT, Instituto de Pesquisa Tecnológica da Escola Politécnica da USP. Escreveu livro para ensino de Física.

\section{Entrevista com Albert Ebert}

Rio de Janeiro, 15/07/2005.

Em que escola o senhor fez o Ginásio no Rio de Janeiro?

O começo foi no Instituto Lafayette ${ }^{4}$ (não existe mais), onde eu fiz desde o Jardim da
Infância, o Primário (1923-1926) e até a quarta série do Ginásio (1927-1930). Na quinta série do Ginásio eu passei para um curso na cidade, no Instituto Superior de Preparatórios (1931). Eu saí do Inst. Lafayette no último ano porque eu já tinha a intenção de cursar História Natural, mas quem ia dar essa disciplina era uma pessoa que já tinha sido meu professor de Latim, e um péssimo professor. Aí eu pensei, eu não vou aprender História Natural com esse professor, e me transferi para o Curso de Preparatórios, em que o professor dessa disciplina era um médico, ótimo professor, César Sales. Ele estava adiantado no ensino, uns quarenta anos, porque ele dava aulas práticas, levava rã para a gente abrir, fazia experiências, fazia excursões. Levava-nos ao Jardim Botânico, ao Jardim Zoológico. Ele tinha uma mentalidade avançada em relação ao ensino para a época. Depois fiz o curso gratuito que era dado na própria Faculdade de Medicina, o Curso Preparatório Pré-Médico, em 1932 e 1933. Eu fiz o vestibular com facilidade, e em 1934, entrei para a Faculdade Nacional de Medicina, da então Universidade do Brasil. Nunca exerci a medicina, porque eu entrei em Medicina para poder ser professor. Era a forma de se ter registro de professor secundário.

Formei-me em 1939 (com 23 anos). Acho que tenho aqui uma fotografia da turma. Comecei a lecionar no quinto ano, em 1938. Casei-me nas férias de julho do sexto ano, em 1939. O meu registro permanente de professor é de 15/06/38, para o curso primário. Para o secundário é de 22/01/46.

Um livro específico para o vestibular eu nunca vi. Estudavam pelos livros de Química que existiam na época. Esses livros eram os do Curso Secundário (e Complementar). Geralmente quem ia fazer vestibular fazia um Curso pré-vestibular particular, e esses cursos davam apostilas da matéria. 


\section{Outras obras publicadas no período de 1930-1941}

VENANCIO Fo, Francisco (1894-1946); MENDONÇA, Edgar Süssekind de. Ciencias fisicas e naturais (Introdução geral as ciencias experimentais) Tomo I. 246p, 1a ed., São Paulo: Nacional, 1932 (BPB, série II, v. 1), Tomo II (BPB v.16). 2aed., 1934

COUTO, Antonio Valente do (1901-). Chimica, Theorica e Pratica, para o curso gymnasial, de accordo com o programa aplicado do Mackenzie College e contendo toda a matéria do programa official do Collegio Pedro II. 386p, São Paulo: Mackenzie, 1931.

Há os livros para a 3aㅡ, 4ạ $5^{a}$ séries do Ensino Secundário Fundamental.

Chimica para a 3aㅗ 4a , 5a séries, volume único. 2ed, São Paulo: Nacional, 1936

Muda a ortografia para Química na 2ed, 36; 3ed, 37; 4ed(última) 1938.

AMARAL, João Batista Pecegueiro do (1899-?). Compêndio de Química, de acordo com o programa oficial da 3a série. $385 p$, Rio de Janeiro: Francisco Alves, 1947

Compêndio de Química Geral e

Mineral, vol.1 de acordo com o programa oficial da 4a série do Curso Fundamental do Ensino Secundário, 285p, Rio de Janeiro: Typ. Baptista de Souza, 1933

Compêndio de Química, de acordo com o programa oficial da 4a série. São Paulo: Nacional, 1939

Compêndio de Química Geral e Mineral, vol.2, de acordo com o programa oficial da 5a série, 176 p, Rio de Janeiro: Typographia São Benedicto, 1933

Compêndio de Química, de acordo com o programa oficial da 5a série. 230p, Rio de Janeiro: Villani e Barbero, 1936

J. B. Pecegueiro do Amaral foi professor do Instituto de Educação do Rio de Janeiro.

ALBUQUERQUE, Miguel Tenório d'. Apontamentos de Chimica Geral para as
Escolas Normais. 330p, Rio de Janeiro: Ed. Jacintho Ribeiro dos Santos, 1931

Primeiro anno de Física e Química. 3a série. De acordo com o programa do Colégio Pedro II e do Instituto de Educação. 386p, Rio de Janeiro: Livr. Jacintho Ribeiro dos Santos, 1933

Publicou também um Compendio de Physica, de 924p em 1931.

Ele publicou especificamente para as aulas de Química das Escolas Normais.

As Escolas Normais também tinham aulas de Física e Química, sendo que na Escola Normal de São Paulo, reaberta em 1880, era a cadeira $\mathrm{n} 05$, exercida pelo médico Paulo Bourroul (1855-1941) de 1880 a 1884, e pelo farmacêutico José Eduardo Macedo Soares, entre 1888 e sua morte em 1918.

SILVA, A. B. Alves da. Lições de FísicoQuímica. 368p, Porto Alegre: Ed. da Livr. do Globo, 1936

Silva escreveu também, entre outros, Elementos de Filosofia Aristotélico-tomista e Introdução à Ciência do Direito.

BASIN, J. REIMPRIMATUR São Paulo, 27 de janeiro de 1932. Monsr. Pereira Barros, v. g.

. Química, curso médio, admissão a varias escolas superiores.

Física e Química, curso médio, admissão ás escolas superiores.

Colégio Pedro II.

Pontos de Química, programa do

Estes livros fazem parte da coleção F. T. D. Livros de Ciencias, um para cada série. Têm capa dura.

FUCHS, Rodolfo. Elementos de Química. 1 ㅇaㅇ ano complementar. 1ed, 68p. Recife: Artes Gráficas, 1933. Para a Escola de Aprendizes Artífices.

MILANO, Miguel. O meu mestre de Chimica, 1ํe․, 129p, São Paulo: Eds. Souza \& Prada, 1935.

GODINHO, Victor (1862-1923). Physica e Chimica 3a série. 332p, São Paulo: Distribuidora Livraria Odeon, 1936 
Victor Godinho era Inspetor Sanitário do Serviço Público, foi cofundador da Escola de Farmácia de São Paulo, em 1898. Professor de Higiene e Microbiologia. Sócio fundador da Liga Paulista contra a Tuberculose, Victor Godinho foi seu presidente pelo período de um ano. Além disso, presidiu a Sociedade Estrada de Ferro Campos do Jordão, conseguindo, com o apoio de Emílio Ribas, os recursos para a construção da ferrovia mais tarde encampada pelo estado, a qual favoreceu o acesso ao sítio de relevo culminante do território paulista, onde se instalaram diversas unidades de atendimento aos tuberculosos.

LOBO, Sebastião. Introdução à Química. 3a série, vol. 1, 246p, Rio de Janeiro: J. R. de Oliveira: Ed. Rio Branco, 1936

AMADO, Gildásio. QUÍMICA para $a$ 3a série do Curso Propedêutico. 300p, Porto Alegre: Globo, 1939

QUÍMICA para a 3a série do Curso Secundário. 200p, São Paulo: Nacional, (BPB v.63)

QUÍMICA para a $4 \underline{a}$ série do Curso Secundário. 316p, São Paulo: Nacional, 1937

QUÍMICA para a 5a série do Curso Secundário. 484p, Porto Alegre: Globo, 1939

PUIG, Ignácio. Curso Geral de Química, 514p, 2ªed., Porto Alegre: do Globo, 1932.

Em 1939 está na 3ạed., revista e suplementada, 561p.

Química. Resumo do Curso

Geral de Química ou Vademecum do químico. Pelo Dr. Daly Jornada Barbosa, 238p, Livr. Selbach, Porto Alegre, 1934-1935. É um resumo do texto anterior Lições de Chimica Geral e Orgânica, 1aed., São Paulo: Nacional, 1936

Elementos Químicos, 3 ano seriado, Porto Alegre: do Globo, 1934, 2aed., 1935

Elementos de Química, 4a série, 316p, Trad. Balbuíno Rambo. Porto Alegre: do Globo, 1935

Química Prática para os

estudantes de química dos Cursos Secundários e Complementar. 487p, Porto Alegre: do Globo, 1938

MARCIANO, Mário. Química. Ciclo Colegial. 3a série do Curso Científico. 447p, Rio de Janeiro: Distr. Francisco Alves, 1948 (Coleção Livros Didáticos F. T. D. )

Irmão marista; escreveu também o correspondente de Física.

FERREIRA, Tristão Feijó. Química. 114p, Curitiba: Coruja, 1948

Pontos de Química, 3ㅇcogial Cient. 188p, 6ed., Porto Alegre: Thurmann, 1960

BRANDÃO, Álvaro Soares (1891-1963) lança em São Paulo: Melhoramentos

Iniciação Chimica de acordo com o programa official da 3a série do Ensino Secundário. 124 p, 1aed., 1933; 2ạed., 1935; 3aed., 1937.

Chimica, de acordo com o programa oficial da 4 a série do Ensino Secundário, 258 p, 1aed., 1928, 2ª̣ed., 1934, 3ㄹed., 1938

- Química, de acordo com o programa oficial da 5a série do Ensino Secundário, 361p, 1aed., 1936, 2ª̣ed., 1937; 3aed., 1940.

Em 1937 estava em preparação: Química para Cursos Complementares

PINTO, Fernando Nogueira. O meu Curso de Chimica de acordo com o programa da 4a série secundaria. 154p, 1aed., Rio de Janeiro: Officina Graphica O Globo, 1936.

1941

. Curso de Chimica, vol. 1, 2ed,

RODRIGUES, José de Bittencourt. Primeiros Elementos de Química, 3ạ série ginasial. 196p, Rio de Janeiro: Tip. Alba, 1935

FACCINI, Mário (1907-1957). Física e Química, 3aㅗ série, 430p, 2ªed., Rio de Janeiro: 
F. Briguiet, 1934; 8ªed., Francisco Alves, 1941;

Física e Química, 785p, 3aed., Rio de Janeiro: F. Briguiet, 1939;

Física e Química, 395p, 4aed., Rio de Janeiro: Francisco Alves, 1941

Física e Química, 395p, 7ạed., Rio de Janeiro: Francisco Alves, 1942;

SUMNER, George; VIEIRA, Ricardo Rodrigues. Química Prática. Química Inorgânica e Química Analítica para os Cursos Fundamental e Complementar. 156p, Rio de Janeiro: Freitas Bastos, 1939

FRÓES, Arlindo Michalscki (Porto Alegre, 1892- RJ, 1971). Química para a 3a série. Iniciação ao estudo dos fenômenos, 503p, 2aed., Rio de Janeiro: J. R. de Oliveira \& C, 1934.

Química para a 4a série. 583p,

Rio de Janeiro: J. R. de Oliveira, 1934;

Química para a 5a série. $623 p$

2aed., Rio de Janeiro: Francisco Alves, 1941

LIBERALLI, C. H. Química, 5a série. Rio de Janeiro: J. R. de Oliveira.

HESSELMANN, Djalma. (Salvador, 1892RJ, 1982). Lições resumidas de química. 124p, 2aed., 1934

LOURENÇO, Oscar Bergström QUIMICA para 3ạ série, 255p, 1ạed., São Paulo: Nacional, 1938; (BPB-80) 2aed., 1938; 3aed., 1941; 4ㄹed. (última) 1942

QUIMICA para 4a série, 337p, 1ed, São Paulo: Nacional, 1938 (BPB-95) 2ed, 1940; 3ed, 1941; 318P, 4ed (última), $1942 \mathrm{e}$ QUIMICA para 5a série, $496 p$, 1ed, São Paulo: Nacional, 1940 (BPB-88), 2ed, 1941; 3ed (última), 1942

\section{Considerações finais}

Nesse período estudado, de 1810 a 1941, nota-se claramente que os autores dos livros escolares de química no Brasil são predominantemente os médicos e os farmacêuticos. Eles eram catedráticos na Faculdade de Medicina do Rio de Janeiro e acumulavam o cargo no Colégio Pedro II. Em segundo lugar vem os religiosos, que escreviam os livros para os colégios católicos. $\mathrm{Em}$ terceiro lugar vêm os engenheiros militares, professores nas escolas militares. Esses professores escreveram os manuais voltados para os alunos das instituições nas quais trabalhavam, o Colégio Pedro II e os correspondentes nas províncias, as escolas militares e as escolas religiosas.

\section{Bibliotecas consultadas}

1-Biblioteca da Faculdade de Educação da Universidade de São Paulo, Avenida da Universidade, 308, CEP 05508-040, Cidade Universitária, São Paulo-SP http://paje.fe.usp.br

Essa Biblioteca contém o acervo da Biblioteca Paulo Bourroul que pertenceu à extinta Escola Normal Caetano de Campos e o acervo da Biblioteca Macedo Soares, da extinta Escola Estadual Prof. Macedo Soares.

Como parte da Biblioteca da FE-USP, encontra-se também a Biblioteca do Livro Didático, BLD, que tem o Banco de Dados LIVRES (Livros Escolares) http://paje.fe.usp.br/estruturas/livres

2-Biblioteca Nacional, Av. Rio Branco, 219, CEP 20040-008 Rio de Janeiro - RJ tel. (21) 30953879 http://www.bn.br

3-Colégio Pedro II. Unidade Escolar Centro, NUDOM Núcleo de Documentação e Memória. Av. Marechal Floriano, 80, CEP 20080-001 Centro. Rio de Janeiro - RJ. http://www.cp2.g12br ou http://www.cp2centro.net e-mail nudom@cp2.g12.br ou nudom.cp2@bol.com.br

4-Biblioteca da UNESP, Universidade Estadual Paulista, Campus de Marília, Av. Hygino Muzzi Filho, 737 Campus Universitário, 19525-900 Marília-SP www.biblioteca.unesp.br Banco de Dados 
Bibliográficos da UNESP: ATHENA bibldiretoria@marilia.unesp.br

5-Biblioteca do Conjunto das QuímicasIQ-USP, Av. Lineu Prestes, 950, CEP 05508000, Cidade Universitária, São Paulo-SP (0xx11) 3091-3670 / 3091-3823 - Fax: (0xx11) 3812-8194bibca@bcq.usp.brBanco de Dados Bibliográficos da USP: DEDALUS www.bcq.usp.br

6-Biblioteca Prof. Joel Martins, da Faculdade de Educação da Unicamp, Rua Bertrand Russel, 801 CEP 13083-970 Barão Geraldo, Campinas-SP http://www.fe.unicamp.br Banco de Dados Bibliográficos da Unicamp: ACERVUS, e-mail bibfe@unicamp.br

7-Acervo IBEP-Nacional, Av. Alexandre Mackenzie, 619, Jaguaré CEP 05322-000 São Paulo-SP acervohistorico@ibepnacional.com.br, $\quad \underline{w w w . e d n a c i o n a l-}$ acervo.com.br

8-Bibliothèque François-Mitterrand, da Bibliothèque Nationale de France. BnF, Département Sciences et techniques. Chimie. 7, Quai François-Mauriac, 75706 Paris Cedex 13, www.bnf.fr
9. Biblioteca Pública do Estado de Pernambuco, (Biblioteca Estadual Presidente Castelo Branco)- Seção de Coleção Pernambucana. Rua João Lira s/n, Parque 13 de maio, Santo Amaro, 50050-550 Recife-PE. (81) 31812647 www.biblioteca.pe.gov.br

\section{Referências Bibliográficas}

${ }^{1}$ Blake, A. V. A. S.; Diccionario bibliographico brazileiro (1883-1902), Conselho Federal da Cultura: Rio de Janeiro, 1970.

${ }^{2}$ Rheinboldt, H. In As Ciências no Brasil; vol. II, Azevedo, F., ed.; Editora da Universidade Federal do Rio de Janeiro: Rio de Janeiro, 1996, cap. 7.

${ }^{3}$ Oliveira, A. L.; José Lourenço de OliveiraEducador, Cuatiara: Belo Horizonte, 1996.

${ }^{4} \mathrm{O}$ Instituto Lafayette era na Rua Haddock Lobo. $O$ prédio ainda existe, mas não é mais colégio. $O$ professor Ebert o considera $O$ melhor colégio daquela época. 